\title{
Reviewing the Influences of Family Environment on Bilingual Education of Preschool Children
}

\author{
Haiyu Ning ${ }^{*}$ \\ Department of Humanities, Chengyi College, Jimei University, Xiamen 361021, China \\ *Corresponding e-mail: 834546076@qq.com
}

Keywords: Home Language Environment, Preschool Children, Second Language Acquisition

\begin{abstract}
Bilingual education is the field of bilingual acquisition, centered on language use or language awareness development. This paper aims to review the influence of the home language environment on preschool children's bilingual education. In this review, previous studies are utilized to respectively analyze subjective and objective factors, such as family socioeconomic status, parental education, and age structure, etc. Through analysis, it has been found that family socioeconomic status and parental education are mostly positively correlated with children's bilingualism, while age structure is always negatively correlated with bilingualism. Greater investment (e.g. finance, time) and monitoring of bilingual learning for children can also promote their bilingual competences when objective conditions (e.g. socioeconomic, age, parental education) are limited.
\end{abstract}

\section{Introduction}

Family plays a vital role in the development of bilingualism among preschool children, as it is children's first language environment. Preschool children in this review refer to students before attending their primary schools and might be currently studying in their kindergartens, whose ages are 3-6 years old. Second language skills need to be developed and improved in daily conversations, and a positive and harmonious home language environment requires parents to create good response mechanisms for their children to develop good language habits. At present, research on bilingual education for preschool children mainly focuses on English-speaking countries, but bilingual studies in Chinese speaking families are rare and mostly limited to kindergartens and classroom environments, paying little attention to the influence of families on children's language skills [1]. In view of this, this study is not only based on the current situation of the family environment in China, but also explains the influence of the family language environment on children's bilingual acquisition in terms of both objective and subjective factors.

\section{The Significance of Bilingual Education to Preschool Children}

Bilingual education is an educational form that learners used two languages for language learning. One could be their native languages; the other one could be their official languages in the countries. Preschool children are at an important stage in their language learning and psychological development [3] since they are more curious of knowledge and more receptive to language than adults and are able to learn and absorb a second language more quickly [4]. Therefore, taking into account the learning characteristics and receptive abilities of preschool children, creating a stable and positive home language environment and response mechanism for them during this period can help them build a relatively stable bilingual foundation. At the same time, it will help them to be more competent in their future learning. Preschool children have efficient and rapid language receptive ability. Hence, some foreign language teaching at this stage is conducive to the better development of children's brains. Language activities within the family can effectively enhance language input, stimulate language development and use, and have a very positive impact on the development of a child's intelligence, thinking, and language skills. Currently, research on the 
home education environment and children's language development mainly focused on Englishspeaking countries, such as the United States, the United Kingdom, and Canada [5]. Based on Ravem's previous literature[6], it is found that the current research mainly focuses on the acquisition and development of monolingual competence and the acquisition of English as a second language among native English-speaking children, but there is little research on their language competence development in the context of family factors.

There are two main ways in which preschool children are exposed to a second language in the early years of their lives: through the kindergarten classroom teacher and through the language environment created by parents at home. However, the knowledge that children acquire in the classroom environment is limited, and the second language environment at home greatly influences the child's future language development. In the past research, scholars from pedagogy, linguistics, psychology, sociology, and other disciplines have carried out in-depth interdisciplinary discussions on family education environment and children's language ability development. More and more evidence shows that the differences in the development of children's second language ability come from different types and different degrees of language contact in the family education environment [7]. The family is a child's immediate living environment and the first environment in which he or she receives education. The quality of the home language environment will directly determine the maturity of children's future language development and will also have a certain degree of influence on the overall quality of preschool children's development. However, the language ability of bilingual learners needs to be formed during the process of practice, and to promote and strengthen the language ability of preschool children, educators and original families should work together to build a positive and harmonious bilingual education environment. The key to a harmonious home language environment is for the child to be expressive, to want to speak, to dare to speak, to speak well, and to receive positive responses. Numerous previous studies have shown that bilingual children excel in various components of executive function, such as inhibitory control, cognitive flexibility, and working memory [8]. In this research, children were administered a measure of receptive vocabulary and an attention-shifting measure of executive function. And two measures from the preschool testing, peg tapping, and item selection, were repeated because the construct they assess, executive function, is central to the study's aims.

\section{Factors that Influence Family Environment on Bilingual Education to Preschool Children}

\subsection{Family Objective Factors}

The family's Socioeconomic Status (SES) directly affects the family's investment in bilingual education for their children. Families with high socioeconomic status are more likely to provide relevant learning resources for their children, and provide solid material guarantees for the formation of a good bilingual family environment and for children to receive good bilingual education. Based on socioeconomic status and family education environment, there are large differences in early language development among individuals. These differences are mainly in phonological, lexical, grammatical, reading and narrative abilities. In McDowell (2007)'s study, the SES status was determined based on the funding source of the preschool the children attended and were dummy coded as higher $S E S=1$, lower $S E S=0$, and the children from lower SES homes comprised $28 \%$ of the sample. In two weeks, children completed two standardized tests of vocabulary, eight tests of phonological awareness, and two speech sound accuracy tasks. Descriptive statistics for age and phonological awareness, vocabulary and speech sound accuracy for children by SES group are presented in Table 1. 
Table 1. Means and standard deviations for chronological age and indices of vocabulary, phonological awareness, and speech sound accuracy for children, by age and socioeconomic status (SES) [9].

\begin{tabular}{|c|c|c|c|c|c|c|c|c|c|c|}
\hline \multirow[b]{2}{*}{ Variable } & \multicolumn{2}{|c|}{$\begin{array}{l}\text { All ages } \\
(n=505)\end{array}$} & \multicolumn{2}{|c|}{$\begin{array}{l}\text { 2-year-olds } \\
(\mathrm{n}=91)\end{array}$} & \multicolumn{2}{|c|}{$\begin{array}{c}3 \text {-year-olds }(\mathrm{n}= \\
145)\end{array}$} & \multicolumn{2}{|c|}{$\begin{array}{c}\text { 4-year-olds } \\
(\mathrm{n}=169)\end{array}$} & \multicolumn{2}{|c|}{$\begin{array}{l}\text { 5-year-olds } \\
(\mathrm{n}=100)\end{array}$} \\
\hline & $M$ & SD & $\mathrm{M}$ & SD & $M$ & SD & $\mathrm{M}$ & SD & $\mathrm{M}$ & $\mathrm{SD}$ \\
\hline \multicolumn{11}{|c|}{ Higher SES } \\
\hline Age (months) & 47.96 & 11.62 & 31.18 & 2.98 & 41.39 & 3.40 & 52.95 & 3.25 & 64.33 & 3.11 \\
\hline \multicolumn{11}{|l|}{ Measure } \\
\hline ENP & 1.56 & 2.36 & 0.02 & 0.15 & 0.52 & 1.28 & 1.96 & 2.44 & 3.76 & 2.64 \\
\hline MCE & 5.61 & 2.08 & 3.96 & 1.81 & 5.39 & 1.96 & 6.20 & 1.81 & 6.43 & 2.02 \\
\hline EW & 3.83 & 4.26 & 0.20 & 0.64 & 1.46 & 2.79 & 5.15 & 4.09 & 8.35 & 2.85 \\
\hline $\mathrm{BNP}$ & 2.44 & 2.41 & 0.85 & 1.33 & 1.43 & 1.58 & 2.90 & 2.20 & 457 & 2.70 \\
\hline MCB & 8.03 & 2.23 & 5.79 & 2.27 & 7.49 & 2.24 & 8.90 & 1.51 & 9.40 & 1.11 \\
\hline BW & 4.56 & 4.11 & 2.18 & 2.76 & 2.80 & 3.11 & 5.56 & 4.11 & 7.58 & 3.96 \\
\hline $\mathrm{RM}$ & 7.42 & 2.66 & 5.30 & 1.70 & 6.18 & 2.17 & 8.31 & 2.42 & 9.63 & 2.01 \\
\hline $\mathrm{RO}$ & 5.37 & 2.71 & 4.04 & 1.60 & 4.61 & 2.30 & 5.61 & 2.80 & 7.30 & 2.81 \\
\hline PPVT-R & 101.45 & 15.93 & 101.68 & 13.89 & 101.10 & 13.90 & 100.51 & 18.18 & 103.32 & 16.44 \\
\hline EOWPVT-R & 105.99 & 16.44 & 107.25 & 14.95 & 102.50 & 12.73 & 106.56 & 18.68 & 108.93 & 17.76 \\
\hline GFTA & 63.86 & 9.17 & 54.93 & 9.84 & 61.79 & 9.13 & 67.20 & 6.27 & 69.55 & 4.32 \\
\hline \multirow[t]{3}{*}{ NWR } & 14.49 & 6.61 & 8.50 & 4.94 & 12.81 & 5.13 & 16.49 & 5.94 & 19.05 & 4.32 \\
\hline & \multicolumn{2}{|c|}{ All ages } & \multicolumn{2}{|c|}{ 2-year-olds } & \multicolumn{2}{|c|}{ 3-year-olds } & \multicolumn{2}{|c|}{ 4-year-olds } & \multicolumn{2}{|c|}{ 5-year-olds } \\
\hline & \multicolumn{2}{|c|}{$(n=195)$} & \multicolumn{2}{|c|}{$(\mathrm{n}=1)$} & \multicolumn{2}{|c|}{$(n=92)$} & \multicolumn{2}{|c|}{$(n=53)$} & \multicolumn{2}{|c|}{$(n=49)$} \\
\hline Variable & $\mathrm{M}$ & SD & $\mathrm{M}$ & SD & $\mathrm{M}$ & SD & $\mathrm{M}$ & SD & $\mathrm{M}$ & SD \\
\hline \multicolumn{11}{|c|}{ Lower SES } \\
\hline Age (months) & 53.02 & 7.65 & 30.00 & - & 43.91 & 2.38 & 53.16 & 3.22 & 63.08 & 2.10 \\
\hline \multicolumn{11}{|l|}{ Measure } \\
\hline ENP & 0.36 & 1.11 & 0.00 & - & 0.11 & 0.32 & 0.11 & 0.52 & 1.12 & 1.90 \\
\hline MCE & 5.04 & 1.59 & 400 & - & 4.60 & 1.76 & 4.97 & 1.53 & 5.67 & 1.34 \\
\hline EW & 1.61 & 3.07 & 0.00 & - & 0.79 & 1.78 & 0.75 & 1.88 & 4.12 & 4.39 \\
\hline BNP & 1.20 & 1.58 & 0.00 & - & 1.04 & 1.48 & 0.84 & 1.39 & 2.08 & 1.73 \\
\hline MCB & 7.99 & 2.02 & 7.00 & - & 6.85 & 2.23 & 7.99 & 1.87 & 9.22 & 1.21 \\
\hline BW & 2.78 & 3.33 & 2.00 & - & 2.09 & 2.60 & 2.60 & 3.21 & 3.89 & 4.04 \\
\hline RM & 6.19 & 2.24 & 2.00 & - & 5.89 & 1.93 & 5.75 & 2.05 & 7.41 & 2.45 \\
\hline RO & 4.90 & 2.46 & 3.00 & - & 464 & 1.96 & 4.59 & 2.29 & 5.82 & 3.03 \\
\hline PPVT-R & 74.73 & 16.10 & 76.00 & - & 79.66 & 17.16 & 70.64 & 15.80 & 77.04 & 13.84 \\
\hline EOWPVT-R & 81.94 & 11.17 & 90.00 & - & 8459 & 11.17 & 79.54 & 10.39 & 83.43 & 11.94 \\
\hline GFTA & 64.34 & 6.77 & 10.00 & - & 61.02 & 7.53 & 65.55 & 5.17 & 67.47 & 3.91 \\
\hline NWR & 13.53 & 5.37 & 11.00 & - & 12.20 & 6.06 & 13.10 & 4.38 & 15.78 & 5.75 \\
\hline
\end{tabular}

Note; Em dashes indicate that only 1 child was in this group; thus, there is no SD. ENP=Elision Nonpicture; MCE-Mutiple Choice Elision; EW=Elision Word; BNP=Blending Nonpicture; MCB=Multiple choice Blending; BW=Blending Word; RM=Rhyme Matching; RO=Rhyme Oddity; PPVT-R=Peabody Picture Vocabulary TestRevised; EOWPVT-R=Expressive One-Word Picture Vocabulary Test-Revised; GFTA=Goldman-Fristoe Test of Articulation; NWR= Nonword Repetition.

The vocabulary measure scores that are reported are standard scores $(M=100, S D=15)$. Table 1 illustrates that scores on all measures are increasing with age and that children from lower SES homes generally performed worse than children from higher SES homes. The study shows that children from higher socioeconomic families are more sensitive to phonological structure, and they 
outperform their peers from lower socioeconomic families in several phonological measures, including rhythm matching, phonological integration, and syllable omission [9].

Blanden and Machin's research on another survey in the UK showed that children from lower socioeconomic families lagged 15 months behind children from higher socioeconomic families of the same age in expressive vocabulary development [10], and their vocabulary development was much slower than that of their peers. In the early stages of grammar learning, there were no significant differences in syntactic acquisition between children of different socioeconomic status. However, as they grow older, significant differences begin to appear in the complexity and variety of their syntactic expressions, i.e., children from high socioeconomic families have significantly higher syntactic complexity than those of the same age [11]. Combining the above data, it is found that family socioeconomic status has a significant impact on second language acquisition in preschool children.

From the sociological point of view, the age structure of the population has a direct impact on the structural changes in the educational ecosystem and the bilingual education of their children to a large extent [12]. Specifically, the proportion of parents educated is much higher in young families than in middle-aged and older families, and the proportion of children educated is also relatively high.

Belaid's research shows that children's intelligence has a relationship with their parents' education, and this relationship becomes stronger as the children grow older [13]. The educational level of the parents reflects their linguistic and cultural competence to a certain extent. In Becky's (2018)study, he found that differences in socioeconomic status led to differences in language input, which was a significant predictor of children's second language proficiency, with learners whose parents had postgraduate education or higher having higher language input and significantly higher second language proficiency than their peers [14]. Parents with higher levels of education are more likely to foster a positive family culture and an open language environment. Nowadays, China is strongly promoting bilingual education for preschool children. Hence, parents who have received higher education are more aware of the importance of early bilingual education to their children's future. Therefore, they are more likely to cooperate with the school's bilingual program.

\subsection{Family Subjective Factors}

In addition, subjective family factors also have a strong influence on the bilingual education of preschool children [15]. One of the most important reasons for the success of bilingual education for preschool children is tremendous parental support for bilingual education. However, if the parents do not have the relevant language knowledge and skills, they need to pay more attention to and monitor the child's bilingual learning so as to lay a solid foundation for bilingualism.

According to Vygotsky (1978)'s theory of cognitive development, the material conditions and physical environment of the family have an important influence on the development of the child. Parents can implement verbal stimulation through games, books, parent-child activities, etc. Greater investment in education and efforts to improve environmental conditions at home and bilingual education can be effective in improving the language skills of young children. From this, it can be concluded that improving the home language environment can start with increased investment in home education. For example, some parents indicated that they would like to provide a more professional language environment for their child by adding equipment, while others indicated that they would like to spend time with their children to share what they learned that day or hire a tutor for additional support.

In addition, parents' beliefs about their role in their children's literacy and language development are an important component of the home educational environment [16]. Typically, parents with higher expectations and acceptance of their children's bilingual learning are correspondingly more willing to invest in bilingual education. Although some families may be influenced by certain objective factors, their supportive attitude towards bilingual education clearly indicates the need for bilingual education for their children. For example, in cases where children have a single pathway to bilingual learning and are economically disadvantaged, parents should provide greater 
encouragement and guidance to their children, as well as actively communicate with teachers. In general, parents' expectation is positively proportional to children's motivation, the higher the expectation, the more intense the effect on children, and thus the confidence and efficiency of bilingual learning will be greatly increased. Many foreign studies have shown that there is a significant difference between the expectations of the middle class with affluent families and higher levels of education and the blue-collar class with lower incomes for children [17]. Parents' active involvement in their children's early literacy activities is significant [18]. Research shows that there is a positive relationship between parents' beliefs about reading and interactive language activities in the home, i.e., the more aware parents are of their own importance, the more involved they are in developing their children's literacy and related skills [19]. Parents can do this by engaging their children in a range of family activities, such as shared book reading and related types of parentchild conversations characterized by the use of rich vocabulary, complex and information-intensive sentences, and semantically interrelated discourse, i.e., discourse commonly thought to stimulate language development and use [20].

\subsection{Future Implication}

The second language competence of preschool children is the result of a combination of objective and subjective developmental factors. Therefore, it is very important to cultivate bilingualism from early childhood and even from birth. Hence, bilinguals' two languages can develop in balance, and even to some extent, compensate for the negative impact of cultural and family economic status deficiencies on children's cognitive development [21]. As Preschool children are in the early stages of language acquisition, their physical, mental, and intellectual development is incomplete, and they passively accept the language environment provided by the family. A good and harmonious family environment can provide with a guarantee for children to receive bilingual education and lay a good foundation for their future bilingual learning. On the contrary, bilingual education is limited to the kindergarten classroom environment, and children's second language ability is likely to regress.

An overview of the current domestic and international research on the family environment and children's language development and its contents are very inspiring to Chinese researchers. This shows that the home language environment, as the first environment in which children form bilingual individuals, directly affects their bilingualism. For laying a good bilingual foundation for children, parents should raise their awareness of bilingual education, reduce their percentages of using monolingual discourse, and actively cooperate with kindergartens in implementing bilingual education in both thoughts and actions. Parents should also optimize the home language environment and expose their children to language immersion to improve the current situation in which some families are not active and cooperative in bilingual education.

\section{Conclusion}

The review explains the influence of home language environment on preschool children's bilingual education based on subjective and objective family factors, respectively. Objective factors (e.g., family socioeconomic status, parental education, second language proficiency) are often positively correlated with preschool children's bilingual acquisition. If there are limited objective conditions, parents can compensate for them by strengthening supervision and guidance and changing their language attitudes to promote bilingual education. The influence of the home environment on children's second language acquisition has always been a hot research topic in the field of bilingual language acquisition, focusing on the development of language skills. Family education is an important factor in the long-term development of children's language skills. Therefore, how can parents establish a good language environment to promote children's language development in ordinary families? Or, in low-income families, what can parents do to change the relatively backward educational environment in order to escape their children's current language development disadvantage? These are research questions that need to be further explored and discussed in future research. 


\section{References}

[1] Lara-Alecio, R., \& Parker, R. I. (1994). A pedagogical model for transitional English bilingual classrooms. Bilingual Research Journal, 18(3-4), 119-133.

[2] Schwartz, M., Mor-Sommerfeld, A., \& Leikin, M. (2010). Facing bilingual education: kindergarten teachers' attitudes, strategies and challenges. Language Awareness, 19(3), 187-203.

[3] McCarthy, D. (1943). Language development in the preschool child.

[4] Conti-Ramsden, G., \& Durkin, K. (2012). Language development and assessment in the preschool period. Neuropsychology review, 22(4), 384-401.

[5] Scheele, A. F., Leseman, P. P., \& Mayo, A. Y. (2010). The home language environment of monolingual and bilingual children and their language proficiency. Applied Psycholinguistics, 31(1), 117-140.

[6] Ravem, R. (1984). Language acquisition in a second language environment. Error analysis: Perspectives on second language acquisition, 124-133.

[7] Yeo, L. S., Ong, W. W., \& Ng, C. M. (2014). The home literacy environment and preschool children's reading skills and interest. Early Education and Development, 25(6), 791-814.

[8] Blair, C., \& Razza, R. P. (2007). Relating effortful control, executive function, and false belief understanding to emerging math and literacy ability in kindergarten. Child development, 78(2), 647663.

[9] McDowell, K. D., Lonigan, C. J., \& Goldstein, H. (2007). Relations among socioeconomic status, age, and predictors of phonological awareness. Journal of Speech, Language, and Hearing Research.

[10] Blanden, J., \& Machin, S. (2010). Intergenerational inequality in early years assessments. Children of the 21st century-the first five years, 153-168.

[11] Vasilyeva, M., Waterfall, H., \& Huttenlocher, J. (2008). Emergence of syntax: Commonalities and differences across children. Developmental science, 11(1), 84-97.

[12] Fan, G.R. (2001). Educational ecology.

[13] Li, S.L. (2006). Home education for preschool children.

[14] Huang, B., Chang, Y. H. S., Niu, L., \& Zhi, M. (2018). Examining the effects of socioeconomic status and language input on adolescent English learners' speech production outcomes. System, 73, 27-36.

[15] De Houwer, A. (1999). Environmental factors in early bilingual development: The role of parental beliefs and attitudes. Bilingualism and migration, 1999, 75-96.

[16] Drummond, K. V., \& Stipek, D. (2004). Low-income parents' beliefs about their role in children's academic learning. The elementary school journal, 104(3), 197-213.

[17] Fang, F.X., \& Fang, G. (2004). Developmental psychology of children.

[18] Sénéchal, M., \& LeFevre, J. A. (2002). Parental involvement in the development of children’s reading skill: A five-year longitudinal study. Child development, 73(2), 445-460.

[19] Weigel, D. J., Martin, S. S., \& Bennett, K. K. (2006). Contributions of the home literacy environment to preschool-aged children's emerging literacy and language skills. Early Child Development and Care, 176(3-4), 357-378.

[20] Deckner, D. F., Adamson, L. B., \& Bakeman, R. (2006). Child and maternal contributions to shared reading: Effects on language and literacy development. Journal of Applied Developmental Psychology, 27(1), 31-41.

[21] Kovelman, I., Baker, S. A., \& Petitto, L. A. (2008). Age of first bilingual language exposure as a new window into bilingual reading development. Bilingualism (Cambridge, England), 11(2), 203. 